\title{
Prevalence of significant peripheral artery disease in patients evaluated for percutaneous aortic valve insertion: Preprocedural assessment with multidetector computed tomography
}

\author{
Vikram Kurra, MD, ${ }^{\text {a,b }}$ Paul Schoenhagen, MD, ${ }^{\text {a,b }}$ Eric E. Roselli, MD, ${ }^{\text {a }}$ Samir R. Kapadia, MD, ${ }^{\text {a }}$. Murat Tuzcu, MD, ${ }^{\text {a }}$ \\ Roy Greenberg, MD, ${ }^{a}$ Mateen Akhtar, MD, ${ }^{a}$ Milind Y. Desai, MD, ${ }^{\mathrm{a}, \mathrm{b}}$ Scott D. Flamm, MD, ${ }^{\mathrm{a}, \mathrm{b}}$ Sandra S. Halliburton, PhD, \\ Lars G. Svensson, MD, ${ }^{a}$ and Srikanth Sola, MD ${ }^{\mathrm{a}, \mathrm{b}}$
}

\begin{abstract}
Objectives: Percutaneous aortic valve insertion is an emerging treatment option for selected patients with severe aortic stenosis and may be done from a transfemoral or transapical approach. Concomitant atherosclerotic peripheral artery disease limits transfemoral access. We evaluated the potential role of multidetector computed tomography in preoperative assessment of vascular anatomy.
\end{abstract}

\begin{abstract}
Methods: Consecutive patients with severe aortic stenosis were included. Contrast-enhanced computed tomographic angiography of the thoracic and abdominal aorta and iliofemoral arteries was performed. Criteria of unfavorable iliofemoral anatomy were defined as a minimal luminal diameter of the common iliac, external iliac, or common femoral arteries of less than $8 \mathrm{~mm}$, presence of greater than $60 \%$ circumferential calcification at the external-internal iliac bifurcation, and severe angulation between the common and external iliac arteries $\left(<90^{\circ}\right)$. The prevalence of these criteria was evaluated and infrarenal aortic and iliofemoral arterial anatomy was compared in the groups with and without peripheral artery disease for any of these criteria.
\end{abstract}

Results: One hundred patients ( $79 \pm 9$ years, 59\% male) were included. A total of $35(35 \%)$ patients had at least one criterion of unsuitable iliofemoral anatomy, including 27 patients with small minimal luminal diameter $(<8 \mathrm{~mm}), 12$ patients with severe circumferential calcification at the iliac bifurcation $(>60 \%)$, and 4 with severe angulation of the iliac arteries $\left(<90^{\circ}\right)$.

Conclusions: Significant atherosclerotic peripheral artery disease is common in the high-risk patient population currently evaluated for percutaneous aortic valve insertion. Computed tomography allows identification of patients with iliofemoral anatomy unfavorable for the transfemoral approach to percutaneous aortic valve insertion.

Percutaneous aortic valve insertion (pAVI) is an emerging therapy for selected patients with severe aortic stenosis who are not candidates for conventional open cardiac surgery owing to significant comorbidities. ${ }^{1-8}$ There is a spectrum of arterial access strategies, ranging from a percutaneous transfemoral approach, open femoral/iliac approach, surgical iliac grafts, to a transapical approach. ${ }^{9-11}$ Because of the large device size of current generation systems, the transfemoral approach requires favorable iliofemoral arterial anatomy. ${ }^{12}$ In the setting of insufficient luminal diameter but also extensive calcification and tortuosity of the iliofemoral arteries, the transfemoral approach is associated

From the Heart \& Vascular Institute ${ }^{\mathrm{a}}$ and the Imaging Institute, ${ }^{\mathrm{b}}$ Cleveland Clinic, Cleveland, Ohio.

Dr Greenberg receives research support from Terarecon, Inc; Gore, Inc. and Cook, Inc. Dr Halliburton receives a research grant from Siemens Healthcare. Dr Desai and Dr Sola have received lecture fees from Philips Healthcare. Dr Roselli has received consulting fees from Medtronic. Dr Flamm has received consulting fees from Vital Images and receives research grants from Philips and Siemens Healthcare. Dr Svensson serves on the scientific advisory board for Edwards LifeSciences, Percutaneous Aortic Valve Clinical Trials, without any financial remuneration.

Received for publication Oct 10, 2008; revisions received Nov 14, 2008; accepted for publication Dec 19, 2008.

Address for reprints: Paul Schoenhagen, MD, Cleveland Clinic, Desk J 1-4, 9500

Euclid Ave, Cleveland, OH 44195 (E-mail: schoenp1@ccf.org).

J Thorac Cardiovasc Surg 2009;137:1258-64

$0022-5223 / \$ 36.00$

Copyright (c) 2009 by The American Association for Thoracic Surgery doi: 10.1016/j.jtcvs.2008.12.013 with a higher incidence of arterial injury. ${ }^{13}$ The prevalence of significant peripheral arterial disease (PAD) in the highrisk population currently undergoing assessment for pAVI is unknown but expected to be high.

Limited angiographic assessment of the iliofemoral anatomy is routinely performed during preprocedural coronary angiography. However, dedicated evaluation of infrarenal aortic and iliofemoral arterial anatomy by multidetector computed tomography (MDCT) might have additional value inasmuch as it allows precise cross-sectional diameter measurements, assessment of the extent and distribution of calcification, and 3-dimensional course/tortuosity of the iliofemoral arteries. This may allow identification of patients with unsuitable iliofemoral anatomy for a transfemoral approach to pAVI and eventually preprocedural planning of arterial access.

The aim of this study was to evaluate the prevalence and characteristics of PAD using computed tomographic (CT) angiography in a patient population undergoing evaluation for pAVI.

\section{METHODS}

\section{Patient Population}

We evaluated 100 consecutive patients with severe, symptomatic aortic stenosis who were referred for MDCT as part of the evaluation for pAVI. Patients with advanced renal insufficiency or other contraindications to 


\section{Abbreviations and Acronyms \\ $\mathrm{CT}=$ computed tomography \\ MDCT $=$ multidetector computed tomography \\ pAVI = percutaneous aortic valve insertion \\ $\mathrm{PAD}=$ peripheral arterial disease}

intravenous contrast dye were excluded from the MDCT evaluation. The study was approved by the institutional review board, with waiver of individual consent.

\section{Dual-Source MDCT}

All subjects were scanned on a dual-source multidetector row CT scanner (MDCT; Siemens Medical Solutions, Definition, Erlangen, Germany) after administration of an iodinated contrast agent $(70-100 \mathrm{~mL}$ of Ultravist $370)$ at $3 \mathrm{~mL} / \mathrm{s}$. All patients were scanned from the level of the thoracic inlet to the level of the mid-thigh region using a nonelectrocardiographically gated helical mode of acquisition with the following parameters: gantry rotation time $=330 \mathrm{~ms}$; beam collimation $=24 \times 1.2 \mathrm{~mm}$; tube voltage $=$ $120 \mathrm{kVp}$; reference tube current $=170$ effective $\mathrm{mAs}$ with anatomic based tube current modulation; beam pitch $=0.6$. Images were reconstructed with 3-mm slice thickness.

\section{MDCT Data Analysis}

The images were analyzed offline by two investigators (V.K., S.S.) on a dedicated workstation (Siemens Leonardo). The investigators were blinded to the subject's clinical status and the angiographic images. The infrarenal abdominal aorta, bilateral common iliac arteries, external iliac arteries, and common femoral arteries were evaluated for the following characteristics: (1) minimal luminal diameter (measured from true shortaxis double oblique images, orthogonal to the vessel center line; the window center and level were adjusted to reduce the effect of calcium blooming on vessel measurements; (2) circumferential extent of calcification at the abdominal aortic bifurcation and at the common iliac artery bifurcation (bifurcation into the external and internal iliac arteries); and (3) tortuosity of the arteries defined by the angle between the common iliac artery and external iliac artery (Figures $1-4$ ).

\section{Prespecified Criteria of Significant PAD}

At the onset of the study, unfavorable iliofemoral anatomy was defined as at least one of the following criteria: minimal luminal diameter of the common iliac, external iliac, or common femoral arteries less than $8 \mathrm{~mm}$, presence of more than $60 \%$ circumferential calcification at the externalinternal iliac bifurcation, and severe angulation between the common and external iliac arteries $\left(<90^{\circ}\right)$ (Figures 1-4).

\section{Statistical Analysis}

All values presented are the mean \pm standard deviation for continuous variables and the percentage of total patients for categorical variables. The independent sample $t$ test and $\chi^{2}$ test were used for comparison of suitable and unsuitable patient groups. All $P$ values were 2 -sided. Calculations were performed with Statistical Package for the Social Sciences (SPSS) software (version 12.0, SPSS, Inc, Chicago, Ill).

\section{RESULTS}

We included 100 consecutive patients $(79 \pm 9$ years, $59 \%$ male). The mean logistic EuroSCORE ${ }^{14}$ was $21.1 \pm 14.3$. Thirty-five $(35 \%)$ patients had at least one of the abovedescribed criteria of significant PAD (PAD group) and 65

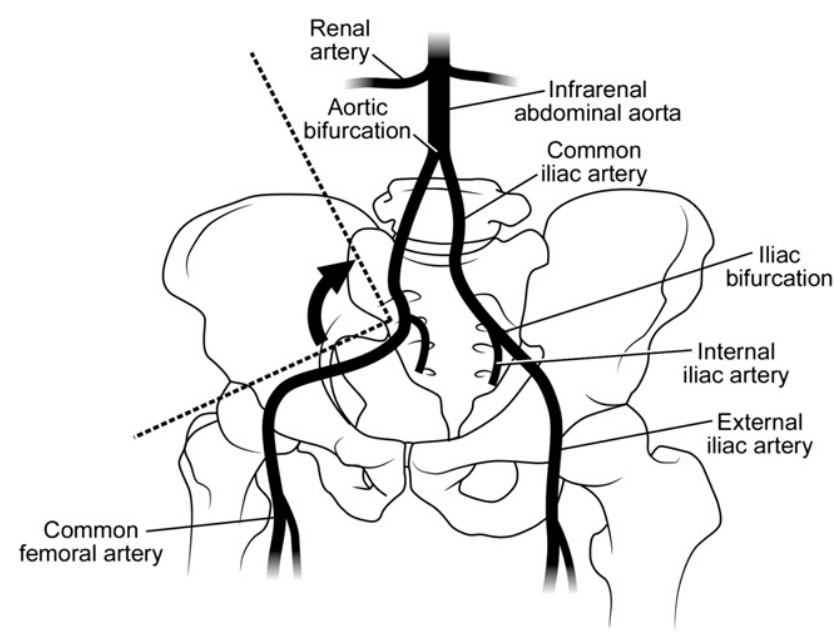

FIGURE 1. Normal infrarenal aortic and iliac anatomy. The angulation between the common and external iliac artery is illustrated.

patients did not meet any criteria for severe PAD (no-PAD group). The PAD group had a statistically significantly higher incidence of coronary artery disease, hypertension, diabetes, chronic obstructive pulmonary disease, prior stroke, obesity, and smoking history than the no-PAD group (Table 1). Because of the long and variable scan ranges required for aortic imaging, typical dose length product values ranged from approximately 600 to $1000 \mathrm{mGy} \times \mathrm{cm}$.

In the PAD group, 27 (77\%) patients had a minimal luminal diameter of less than $8 \mathrm{~mm}$ in at least one location. Twelve $(34 \%)$ patients had severe calcification at the iliac bifurcation, including 9 patients who had severe bilateral calcification. Four $(11 \%)$ patients had severe $\left(<90^{\circ}\right)$ angulation at the common iliac artery and external iliac artery. The mean angle between the right common iliac artery and external iliac artery was $115^{\circ} \pm 20^{\circ}$. The mean angle between the left common iliac artery and external iliac artery was $120^{\circ} \pm 17^{\circ}$. Among the 35 patients with unfavorable anatomy, $7(20 \%)$ had more than one of these criteria and $2(6 \%)$ had all three criteria. Of these 35 patients, 8 patients also had significant atherosclerotic changes of the abdominal aorta, including extreme tortuous course of the infrarenal abdominal aorta $(\mathrm{n}=$ 4; $11 \%$ ), infrarenal abdominal aortic aneurysm diameter greater than $3.5 \mathrm{~cm}(\mathrm{n}=2,6 \%)$, and infrarenal penetrating ulceration $(\mathrm{n}=2 ; 6 \%)$.

Comparison between the group of patients with (PAD group/unfavorable anatomy) and without (no-PAD group/ favorable anatomy) any of these criteria showed significant differences of clinical characteristics and anatomy of the infrarenal and iliofemoral arteries. In the PAD group, the mean luminal diameter at several levels including the infrarenal abdominal aorta, common iliac arteries, external iliac arteries, and common femoral arteries was significantly smaller than in the no-PAD group (Table 2). In the PAD group, $6(17 \%)$ patients had infrarenal abdominal aorta 

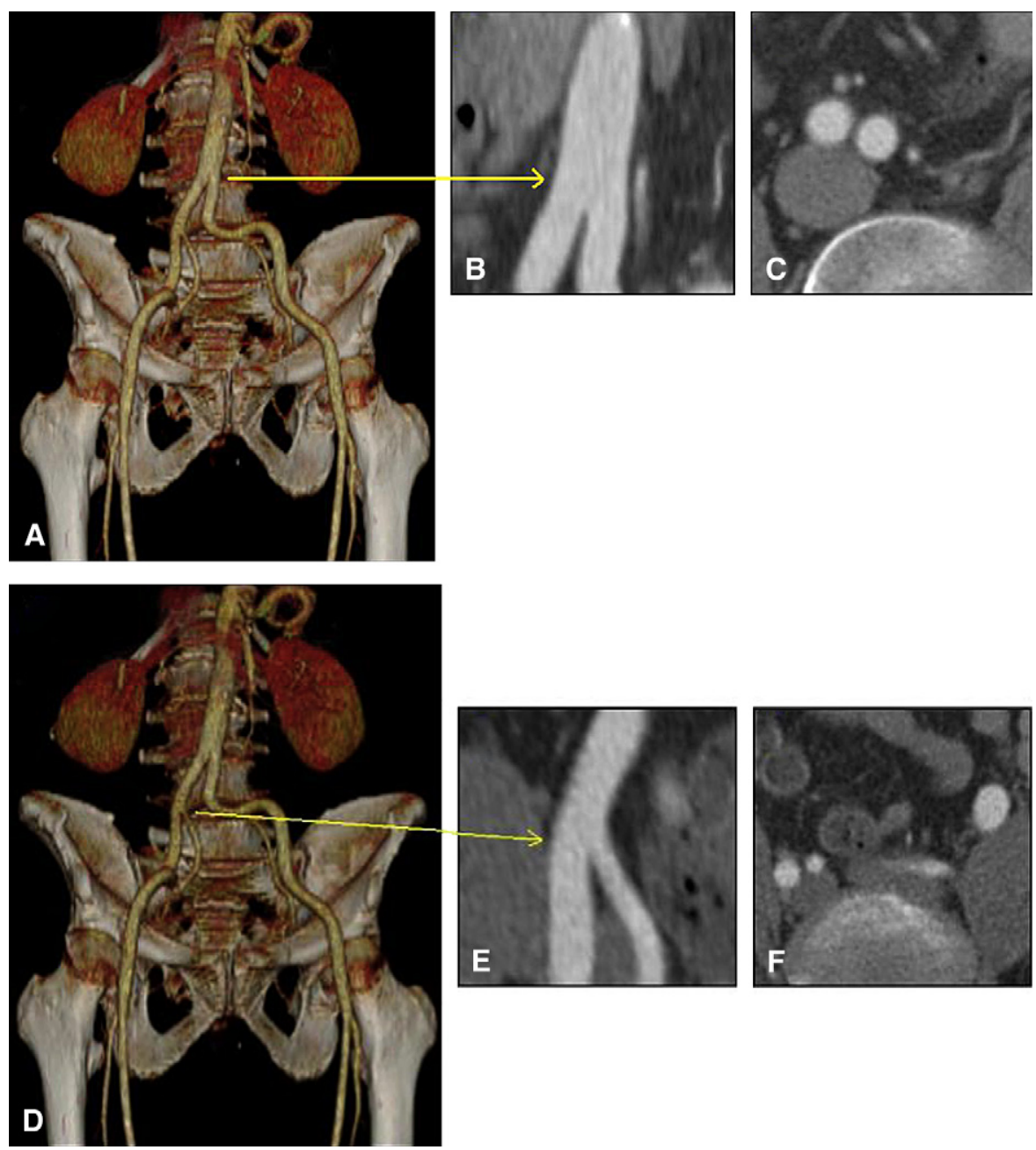

FIGURE 2. Volume-rendered image (A), coronary (B), and axial (C) images of the aortic bifurcation. Volume-rendered image (D), coronary (E), and axial (F) images of the iliac bifurcation.

luminal diameter less than $12 \mathrm{~mm}, 7(20 \%)$ patients had dense calcification at the aortic bifurcation, and $12(34 \%)$ patients had dense calcification $(>60 \%)$ at iliac bifurcation. In contrast, in the no-PAD group, none $(0 \%)$ of the patients had a luminal diameter of the abdominal aorta less than 12 $\mathrm{mm}$, and $5(8 \%)$ patients had dense calcification at the aortic bifurcation (Table 3 ).

Of the 35 patients with MDCT criteria of unfavorable iliofemoral anatomy, 5 patients underwent pAVI via a transfemoral approach. Of these 5 patients, 2 had vascular complications related to the access site (bleeding, focal dissection) requiring surgical intervention. The remaining 3 patients had no procedural complications. In contrast, of the 65 patients without high-risk MDCT criteria, 7 patients underwent transfemoral pAVI. Of these 7 patients, only 1 had a vascular complication $(P$ value $=$ not significant $)$.

\section{DISCUSSION}

Using CT angiography of the infrarenal abdominal aorta and iliofemoral arteries, we found that one third of patients with severe aortic stenosis evaluated for pAVI had anatomic criteria of unfavorable atherosclerotic iliofemoral disease. Of these patients, a majority $(77 \%)$ demonstrated small luminal narrowing $(<8 \mathrm{~mm})$ of the iliofemoral arteries; the remaining $23 \%$ showed other criteria of advanced disease, including circumferential calcification and severe tortuosity, despite sufficient luminal diameter. Comparison between the groups of patients with and without any of these criteria demonstrated that the presence of any one of these criteria identifies a high-risk group of patient with significantly higher clinical risk profile and more unfavorable anatomy of the entire infrarenal and iliofemoral arteries.

At the current time, pAVI is limited to selected patients with severe aortic stenosis who have a risk of death exceeding $15 \%$ with conventional surgery and are not candidates for traditional open cardiac surgery. ${ }^{1-11}$ These patients constitute a high-risk population with significant short-term mortality. ${ }^{15-17}$ Because of the known overlap of etiology and risk factors for atherosclerotic vascular disease and 

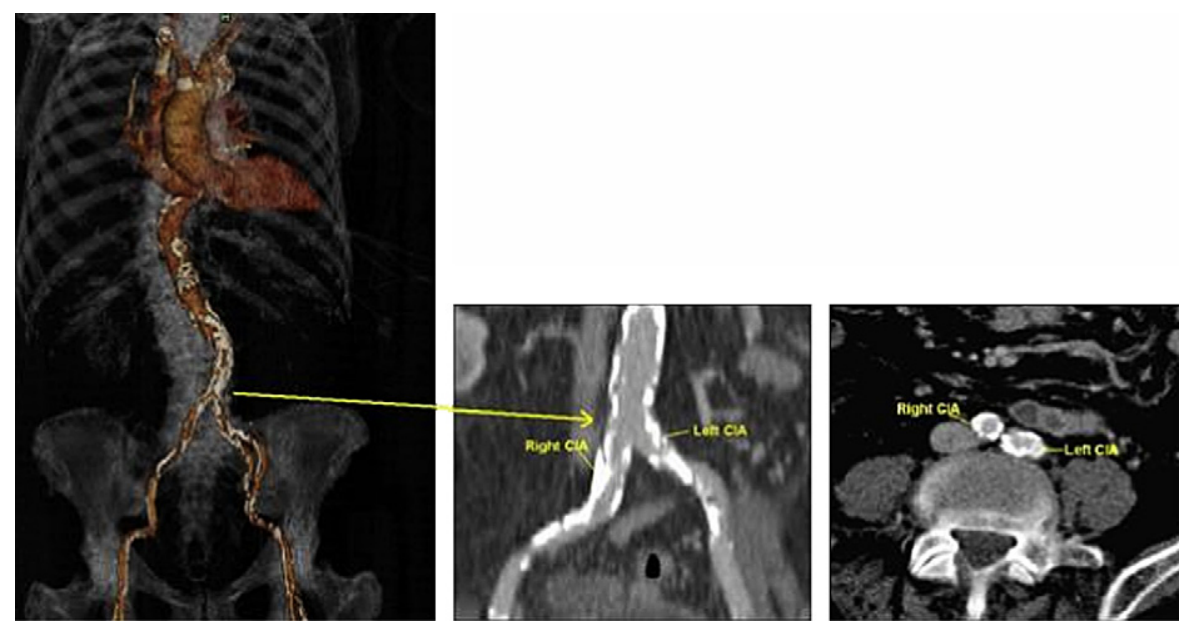

FIGURE 3. Severe atherosclerotic changes of the infrarenal abdominal aorta and iliac arteries. The left panel shows a volume rendered image. The middle panel shows a coronary multiplanar reconstruction (MPR). The right sided panels show axial MPR images at the level of the infrarenal abdominal aorta, aortic and iliac bifurcation. CIA, Common iliac artery.

aortic stenosis, it is not surprising to find a high number of patients with PAD in this population. ${ }^{18}$ Advanced PAD has been associated with increased risk of peripheral complications in other endovascular procedures. ${ }^{12}$ In fact, in one of the first reports of successful human pAVI in a patient with aortic stenosis and pre-existing PAD, progressive worsening of the leg ischemia, leg amputation with lack of healing, infection, and death 17 weeks after PHV implantation was reported. ${ }^{19}$

Preprocedural understanding of arterial anatomy is important to avoid these complications, in particular because there is a spectrum of alternative arterial access strategies, ranging from a percutaneous transfemoral approach, open femoral approach, surgical iliac access grafts, to a transapical approach. Current devices are still relatively large, and advancing these large and relatively stiff devices is limited not only by luminal diameter, but also by vessel calcification (and subsequent distensibility) and tortuosity. Although limited iliofemoral angiography is routinely used in the preoperative assessment of these patients, evaluation of iliofemoral anatomy by MDCT allows more definitive assessment of the 3-dimensional course of the pelvic arteries and distribution and extent of calcification. Data about preprocedural imaging in the context of pAVI is limited. However,
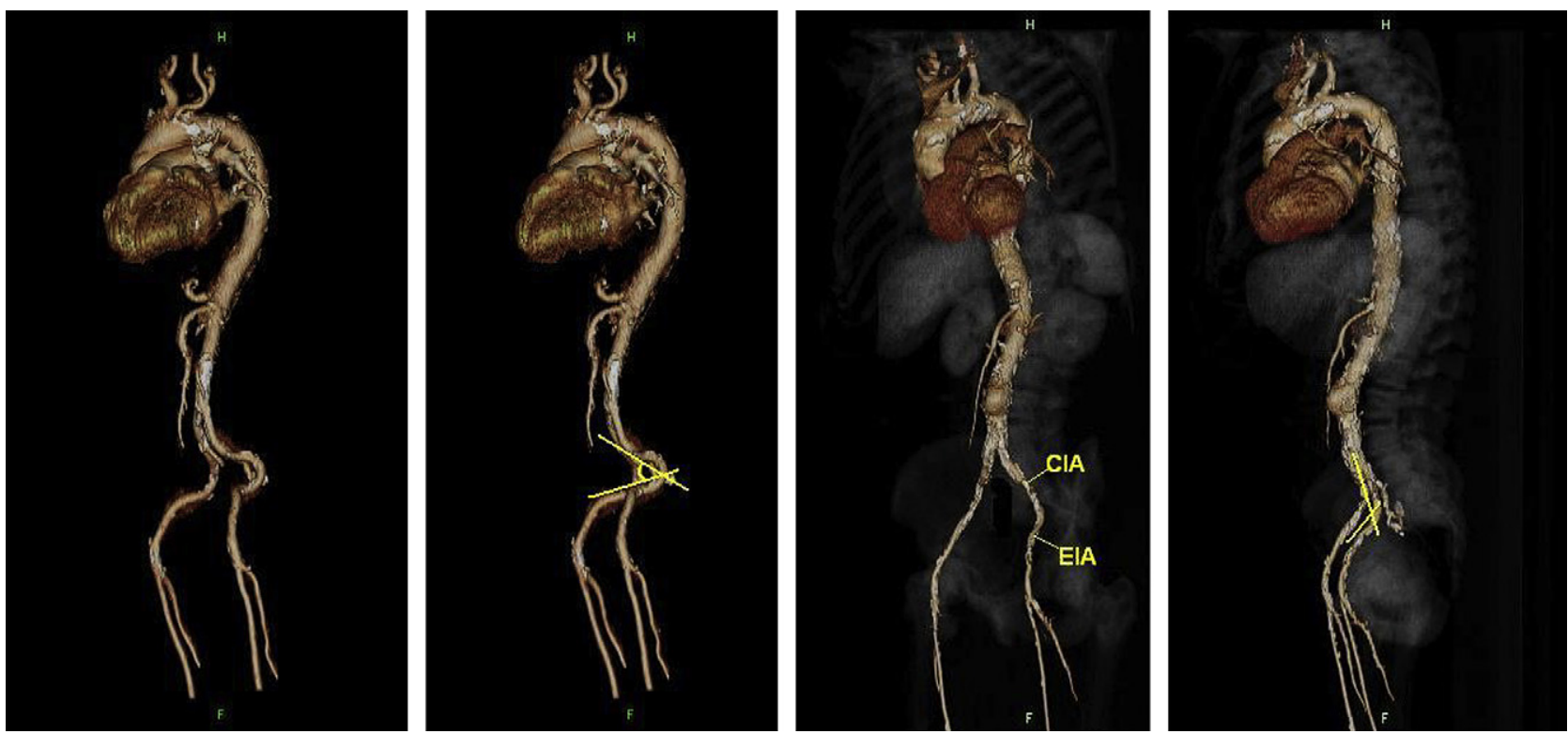

FIGURE 4. Volume-rendered images demonstrating a patient with steep and shallow angle between the common and external iliac arteries. CIA, Common iliac artery; EIA, external iliac artery. 
TABLE 1. Baseline demographics of the 100 patients with aortic stenosis and in the groups with (PAD group) and without (no-PAD group) criteria of significant PAD

\begin{tabular}{|c|c|c|c|c|}
\hline Characteristic & All patients $(n=100)$ & PAD group $(n=35)$ & No-PAD group $(n=65)$ & $P$ value (PAD vs no-PAD) \\
\hline Age (y) & $79 \pm 9$ & $78 \pm 7$ & $80 \pm 9$ & .07 \\
\hline Male gender, $\%(n)$ & $59 \%(59)$ & $48 \%(17)$ & $60 \%(42)$ & .02 \\
\hline Body mass index & $27.9 \pm 3.2$ & $28.6 \pm 3.8$ & $26.6 \pm 3.5$ & .02 \\
\hline Diabetes, \% (n) & $44 \%(44)$ & $52 \%(16)$ & $41 \%(28)$ & .02 \\
\hline Hypertension, \% (n) & $74 \%(74)$ & $80 \%(28)$ & $70 \%(46)$ & .02 \\
\hline Dyslipidemia, \% (n) & $72 \%(72)$ & $60 \%(21)$ & $78 \%(51)$ & .5 \\
\hline Prior stroke, \% (n) & $9 \%(9)$ & $12 \%(4)$ & $7 \%(5)$ & .05 \\
\hline Prior MI, \% (n) & $14 \%(14)$ & $20 \%(7)$ & $11 \%(7)$ & $<.01$ \\
\hline Prior CABG, $\%(n)$ & $42 \%(42)$ & $40 \%(14)$ & $43 \%(28)$ & .04 \\
\hline Severe COPD, \% (n) & $40 \%(41)$ & $46 \%(16)$ & $38 \%(25)$ & .02 \\
\hline Smoking history, \% (n) & $60 \%(60)$ & $71 \%(25)$ & $52 \%(35)$ & .03 \\
\hline Previous cardiac surgery, $\%(\mathrm{n})$ & $58 \%(58)$ & $54 \%(19)$ & $60 \%(39)$ & .08 \\
\hline Logistic EuroSCORE & $21.1 \pm 14.3$ & $18.1 \pm 12.3$ & $22.3 \pm 14.2$ & .81 \\
\hline $\mathrm{CAD}, \%$ (n) & $78 \%(78)$ & $86 \%(30)$ & $74 \%(48)$ & .001 \\
\hline LVEF (\%) & $48 \pm 14$ & $50 \pm 9$ & $48 \pm 13$ & $<.001$ \\
\hline Peak gradient & $75 \pm 26$ & $78 \pm 22$ & $72 \pm 24$ & .3 \\
\hline $\operatorname{AVA}\left(\mathrm{cm}^{2}\right)$ & $0.7 \pm 0.2$ & $0.6 \pm 0.1$ & $0.7 \pm 0.2$ & .01 \\
\hline Creatinine (mg/dL) & $1.1 \pm 0.4$ & $1.1 \pm 0.6$ & $1.0 \pm 0.3$ & $<.001$ \\
\hline
\end{tabular}

$P A D$, Peripheral arterial disease; $M I$, myocardial infarction; $C A B G$, coronary artery bypass grafting; $C O P D$, chronic obstructive pulmonary disease; $C A D$, coronary artery disease; $L V E F$, left ventricular ejection fraction; $A V A$, aortic valve area.

preprocedural interventional planning is widely established and routinely performed in the context of aortic endovascular stent procedures, and it gains importance for novel surgical and interventional procedures, including hybrid surgical/endovascular procedures and robotic surgery. ${ }^{20-23}$

The importance for planning of vascular access may diminish with the development of pAVI valve delivery systems with small diameters. However, our data suggest that the identification of the above-described criteria of unfavorable iliofemoral anatomy may identify a high-risk group of patients in whom careful planning of access strategy may be of particular importance.

\section{LIMITATIONS}

The criteria used to define unfavorable iliofemoral anatomy in the current study were arbitrarily defined by consensus of the investigators at the onset of the study. These criteria were based on a review of the literature ${ }^{13}$ and also current size of the sheaths used in the procedure. For the transfemoral approach, the external diameter for the 23$\mathrm{mm}$ Edwards stent valve insertion sheath (Edwards LifeSciences, Irvine, Calif) is $24 \mathrm{~F}$ (7.7-mm diameter) and for the $26-\mathrm{mm}$ stent valve, the external sheath size is $28 \mathrm{~F}(9.0$ $\mathrm{mm})$. Assuming some arterial distensibility, a cutoff of 8 $\mathrm{mm}$ was initially deemed reasonable. However, with increasing experience, this approach appears conservative and access through vessels of $7 \mathrm{~mm}$ or more (in the absence of circumferential calcification) has been successful. The current study was not designed to define precise inclusion/ exclusion criteria or to examine whether these criteria correlated with screening angiogram. Procedural and clinical outcome and the reported outcome data are preliminary. Results from ongoing and future clinical studies will need to define the prognostic value of high-risk criteria on clinical outcome

TABLE 2. Mean luminal diameter of the infrarenal abdominal aorta and iliofemoral arteries in the overall group and in the groups with (PAD group) and (no-PAD group) criteria of significant PAD

\begin{tabular}{lcccc}
\hline \multicolumn{5}{c}{ Mean luminal diameter $(\mathbf{m m} \pm \mathbf{S D})$} \\
\hline \multicolumn{1}{c}{ Arterial segment $(\mathbf{m m})$} & All patients $(\mathbf{n}=\mathbf{1 0 0})$ & PAD group $(\mathbf{n}=\mathbf{3 5})$ & No-PAD group $(\mathbf{n}=\mathbf{6 5})$ & $\boldsymbol{P}$ value $($ PAD vs no-PAD) \\
\hline Infrarenal abdominal aorta & $16.4 \pm 2.7$ & $15.2 \pm 2.6$ & $17.2 \pm 2.9$ & .02 \\
Right common iliac artery & $10.6 \pm 1.8$ & $9.4 \pm 1.8$ & $11.3 \pm 1.5$ & .01 \\
Right external iliac artery & $8.6 \pm 1.4$ & $7.1 \pm 1.1$ & $9.2 \pm 0.9$ & .01 \\
Right common femoral artery & $8.7 \pm 1.2$ & $7.3 \pm 1.2$ & $9.3 \pm 0.9$ & $<.001$ \\
Left common iliac artery & $10.4 \pm 1.6$ & $9.4 \pm 1.6$ & $10.9 \pm 1.4$ & .03 \\
Left external iliac artery & $8.5 \pm 1.3$ & $7.4 \pm 0.9$ & $9.2 \pm 1.1$ & .001 \\
Left common femoral artery & $8.6 \pm 1.2$ & $7.5 \pm 1.1$ & $9.2 \pm 0.9$ & .01 \\
\hline PAD, Peil
\end{tabular}

$P A D$, Peripheral arterial disease; $S D$, standard deviation. 
TABLE 3. Circumferential calcification and abdominal aortic aneurysm in the overall group and in the groups with (PAD group) and (no-PAD group) criteria of significant PAD

\begin{tabular}{|c|c|c|c|c|}
\hline Variable & All patients $(n=100)$ & PAD group $(\mathbf{n}=35)$ & noPAD group $(n=65)$ & $P$ value (PAD vs no-PAD) \\
\hline Infrarenal AAA $(>3.5 \mathrm{~cm})$ & $5(5 \%)$ & $2(6 \%)$ & $3(4 \%)$ & .8 \\
\hline Infrarenal aorta $<12 \mathrm{~mm}$ & $6(6 \%)$ & $6(17 \%)$ & $0(0 \%)$ & .22 \\
\hline $\begin{array}{l}\text { Circumferential calcification aortic } \\
\text { bifurcation }(>60 \%)\end{array}$ & $12(10 \%)$ & $7(20 \%)$ & $5(8 \%)$ & .01 \\
\hline $\begin{array}{l}\text { Circumferential calcification iliac } \\
\text { bifurcation }(>60 \%)\end{array}$ & $12(12 \%)$ & $12(34 \%)$ & $0(0 \%)^{*}$ & .2 \\
\hline
\end{tabular}

$P A D$, Peripheral arterial disease; $A A A$, abdominal aortic aneurysm. *B definition

and will be the basis for evidence-based clinical guidelines. ${ }^{24,25}$

A limitation of precise measurements of luminal dimensions with MDCT is partial volume averaging of calcium (calcium blooming). ${ }^{26}$ Blooming of vessel wall calcification is associated with overestimation of the calcified plaque area and luminal stenosis. On the other hand, CT angiography is not limited to a few angiographic planes but allows crosssectional measurements of the vessels at any point along the vessel centerline.

MDCT is limited by the need for iodine-based contrast administration. This is a serious limitation in the current high-risk population, in which limiting the administration of potentially nephrotoxic agents is of utmost importance. Our group has systematically examined clinical characteristics and outcome of patient with severe symptomatic aortic stenosis in a similar but not identical patient population referred for percutaneous aortic valve replacement. In this population of 92 patients, $10(11 \%)$ had chronic kidney disease, defined as a serum creatinine level greater than $2 \mathrm{mg} /$ $\mathrm{dL}{ }^{27}$ The potential value of a noncontrast MDCT to assess calcification and angulation of iliofemoral anatomy has not been evaluated to date. MDCT is also associated with significant radiation exposure. ${ }^{28}$ Although it is generally important to minimize radiation exposure, the risk of deleterious effects is of less concern in this elderly and high-risk population that is currently evaluated for pAVI. ${ }^{28}$

Our data describe results in 100 patients selected for preoperative MDCT assessment by the referring physician. This population may be biased because of the exclusion of patients with contraindications to CT. However, the pattern is similar to a similar but not identical patient population of patients with severe symptomatic aortic stenosis referred for percutaneous aortic valve replacement. Our group has systematically examined clinical characteristics and outcome. ${ }^{27}$

\section{CONCLUSION}

Using CT angiography of the infrarenal abdominal aorta and iliofemoral arteries, we demonstrated that more than one third of patients with severe aortic stenosis evaluated for pAVI had anatomic criteria unfavorable for transfemoral access owing to atherosclerotic changes. CT angiography allows preprocedural planning of arterial access. The clinical impact on decision-making and outcome will need to be evaluated in future controlled clinical trials.

\section{References}

1. Iung B, Baron G, Butchart EG, Delahaye F, Gohlke-Bärwolf C, Levang OW, et al. A prospective survey of patients with valvular heart disease in Europe: the Euro Heart Survey on Valvular Heart Disease. Eur Heart J. 2003;24:1231-43.

2. Boudjemline Y, Bonhoeffer P. Steps towards percutaneous aortic valve replacement. Circulation. 2002;105:772-8.

3. Cribier A, Eltchaninoff H, Tron C, Bauer F, Agatiello C, Sebagh L, et al. Early experience with percutaneous transcatheter implantation of heart valve prosthesis for the treatment of end-stage inoperable patients with calcific aortic stenosis. J Am Coll Cardiol. 2004;43:698-703.

4. Grube E, Laborde JC, Gerckens U, Felderhoff T, Sauren B, Buellesfeld L, et al. Percutaneous implantation of the CoreValve self-expanding valve prosthesis in high-risk patients with aortic valve disease: the Siegburg first-in-man study. Circulation. 2006;114:1616-24.

5. Grube E, Schuler G, Buellesfeld L, Gerckens U, Linke A, Wenaweser P, et al. Percutaneous aortic valve replacement for severe aortic stenosis in high-risk patients using the second- and current third-generation self-expanding CoreValve prosthesis: device success and 30-day clinical outcome. J Am Coll Cardiol. 2007;50: 69-76.

6. Webb JG, Chandavimol M, Thompson CR, Ricci DR, Carere RG, Munt BI, et al. Percutaneous aortic valve implantation retrograde from the femoral artery. Circulation. 2006;113:842-50.

7. Webb JG, Pasupati S, Humphries K, Thompson C, Altwegg L, Moss R, et al. Percutaneous transarterial aortic valve replacement in selected high-risk patients with aortic stenosis. Circulation. 2007;116:755-63.

8. Svensson LG. Aortic valve stenosis and regurgitation: an overview of management. J Cardiovasc Surg (Torino). 2008;49:297-303.

9. Svensson LG, Dewey T, Kapadia S, Roselli EE, Stewart A, Williams M, et al. United States feasibility study of transcatheter insertion of a stented aortic valve by the left ventricular apex. Ann Thorac Surg. 2008;86:46-54.

10. Lichtenstein SV, Cheung A, Ye J, Thompson CR, Carere RG, Pasupati S, et al Transapical transcatheter aortic valve implantation in humans: initial clinical experience. Circulation. 2006;114:591-6.

11. Ye J, Cheung A, Lichtenstein SV, Pasupati S, Carere RG, Thompson CR, et al. Six-month outcome of transapical transcatheter aortic valve implantation in the initial seven patients. Eur J Cardiothorac Surg. 2007;31:16-21.

12. Tops LF, Kapadia SR, Tuzcu EM, Vahanian A, Alfieri O, Webb JG, et al. Percutaneous valve procedures: an update. Curr Probl Cardiol. 2008;33:417-57.

13. Murray D, Ghosh J, Khwaja N, Murphy MO, Baguneid MS, Walker MG. Access for endovascular aneurysm repair. J Endovasc Ther. 2006;13:754-61.

14. Nashef SA, Roques F, Michel P, Gauducheau E, Lemeshow S, Salamon R. European system for cardiac operative risk evaluation (EuroSCORE). Eur J Cardiothorac Surg. 1999;16:9-13.

15. Jamieson WRE, Edwards FH, Schwartz M, Bero JW, Clark RE, Grover FL. Risk stratification for cardiac valve replacement. National cardiac surgery database. Ann Thorac Surg. 1999;67:943-51.

16. Otto CM, Mickel MC, Kennedy JW, Alderman EL, Bashore TM, Block PC, et al. Three year outcome after balloon aortic valvuloplasty: insight into prognosis of valvular aortic stenosis. Circulation. 1994;89:642-50. 
17. Lieberman EB, Bashore TM, Hermiller JB, Wilson JS, Pieper KS, Keeler GP, et al. Balloon aortic valvuloplasty in adults: failure of procedure to improve long-term survival. J Am Coll Cardiol. 1995;26:1522-8.

18. Goldbarg SH, Elmariah S, Miller MA, Fuster V. Insights into degenerative aortic valve disease. J Am Coll Cardiol. 2007;50:1205-13.

19. Cribier A, Eltchaninoff H, Bash A, Borenstein N, Tron C, Bauer F, et al. Percutaneous transcatheter implantation of an aortic valve prosthesis for calcific aortic stenosis: first human case description. Circulation. 2002;106:3006-8.

20. Roselli EE, Greenberg RK, Pfaff K, Francis C, Svensson LG, Lytle BW. Endovascular treatment of thoracoabdominal aortic aneurysms. J Thorac Cardiovasc Surg. 2007; $133: 1474-82$

21. Peterson BG, Longo GM, Matsumura JS, Kibbe MR, Morasch MD, Cardeira KR, et al. Endovascular repair of thoracic aortic pathology with custom-made devices. Surgery. 2005;138:598-605.

22. Greenberg RK, Haddad F, Svensson L, O'Neill S, Walker E, Lyden SP, et al. Hybrid approaches to thoracic aortic aneurysms: the role of endovascular elephant trunk completion. Circulation. 2005;112:2619-26.

23. Falk V, Mourgues F, Adhami L, Jacobs S, Thiele H, Nitzsche S, et al. Cardio navigation: planning, simulation, and augmented reality in robotic assisted endoscopic bypass grafting. Ann Thorac Surg. 2005;79:2040-7.

24. Bonow RO, Carabello BA, Kanu C, de Leon AC Jr, Faxon DP, Freed MD, et al. ACC/AHA 2006 guidelines for the management of patients with valvular heart disease: a report of the American College of Cardiology/American Heart Association Task Force on Practice Guidelines (writing committee to revise the 1998 Guidelines for the Management of Patients With Valvular Heart Disease): developed in collaboration with the Society of Cardiovascular Anesthesiologists: endorsed by the Society for Cardiovascular Angiography and Interventions and the Society of Thoracic Surgeons. Circulation. 2006;114:e84-231.

25. Vahanian A, Alfieri O, Al-Attar N, Antunes M, Bax J, Cormier B, et al. Transcatheter valve implantation for patients with aortic stenosis: a position statement from the European Association of Cardio-Thoracic Surgery (EACTS) and the European Society of Cardiology (ESC), in collaboration with the European Association of Percutaneous Cardiovascular Interventions (EAPCI). Eur Heart J. 2008;29: 1463-70.

26. Alkadhi H, Scheffel H, Desbiolles L, Gaemperli O, Stolzmann P, Plass A, et al. Dual-source computed tomography coronary angiography: influence of obesity, calcium load, and heart rate on diagnostic accuracy. Eur Heart J. 2008;29:766-76.

27. Kapadia SR, Svensson L, Goel S, Wallace L, Rodriguez R, Stewart W, et al. Characterization and outcome of patients with severe symptomatic aortic stenosis referred for percutaneous aortic valve replacement. J Thorac Cardiovasc Surg. 2009 March 25 [Epub ahead of print].

28. Einstein AJ, Henzlova MJ, Rajagopalan S. Estimating risk of cancer associated with radiation exposure from 64-slice computed tomography coronary angiography. JAMA. 2007;298:317-23. 